Original article

\title{
R-banding pattern of the prometaphase chromosomes of the domestic sheep Ovis aries $L$.
}

\author{
D. Di Berardino 1, M.B. Lioi 2, C. Miranda 1, A. Di Milia 1, \\ M.G. D'Agostino ${ }^{1}$ and D. Matassino ${ }^{1}$ \\ 1 University of Naples, Department of Animal Production, 80055 Portici, Naples \\ 2 University of Basilicata, Institute of Animal Production, 85100, Potenza, Italy
}

(received 19-2-1988, accepted 5-5-1988)

Summary - The RBA-banding pattern of the domestic sheep Ovis aries L. and the diagrammatic representation at the $\mathbf{5 1 0}$ band stage are presented and proposed as the "standard" RBA-karyotype for this species.

domestic sheep - RBA-banding - chromosomes

Résumé - Description des chromosomes marqués en bandes $\mathbf{R}$ du mouton domestique Ovis aries L. Les bandes $R$ (technique RBA) des chromosomes du mouton domestique et son idiogramme à l'état de 510 bandes sont présentés et proposés comme le caryotype "standard" de cette espèce.

mouton domestique - bandes $R$ - chromosomes

\section{Introduction}

The discovery of the RBA-banding procedure by Dutrillaux et al. (1973) has provided a remarkable improvement in the identification and description of individual chromosomes of mammals, including man. The benefits of this technique are quite evident in the family Bovidae, whose chromosomes, especially the smallest elements of the karyotype, are not easily distinguishable when G-banded; the difficulty lies in the fact that in Bovidae chromosomes, both centromeres and telomeres are mostly G-negative and, therefore, the smallest autosomes have to be identified by relying upon very few and often undefined bands.

The potential of the RBA-banding technique for definite identification of Bovidae chromosomes, first pointed out by Popescu (1975) and by Gustavsson and Hagelthorn (1976), has subsequently been demonstrated by another series of studies on the R-banding pattern of prometaphase chromosomes of Bos taurus L. (Di Berardino et al., 1979, 1985; Di Berardino and lannuzzi, 1982), Bubalus bubalis L. (Di Berardino et al., 1981; Di Berardino and lannuzzi, 1981, 1984) and Capra hircus L. (Di Berardino et al., 1987). 
As a contribution to establishment of the standard RBA-banded karyotype of Ovis aries L., this paper presents karyotypes and diagrammatic representations of the RBAbanding patterns at the 510 band stage.

\section{Materials and Methods}

Peripheral blood drawn from the jugular vein of 11 animals of the Gentile di Puglia breed (6 males and 5 females) was cultured for $72 \mathrm{~h}$ in RPMI 1640 medium (Flow, Dutch modification), supplemented with $10 \%$ fetal calf serum (Gibco), antibacterial and antifungal agents, $0.1 \%$ of L-glutamine, and pokeweed mitogen (Gibco). After $48 \mathrm{~h}$, lymphocytes were synchronized by adding excess thymidine $(0.3 \mathrm{mg} / \mathrm{ml}$, final concentration). The S-phase block was released $18 \mathrm{~h}$ later by washing the cultures in fresh RPMI medium. To induce R-banding the cells were recultured in growth medium as described above, supplemented with BrdU (Sigma, $10 \mu \mathrm{g} / \mathrm{ml}$, final conc.) added $1 \mathrm{~h}$ later. The optimal recovery time was found to be around $6.5 \mathrm{~h}$, including $1 \mathrm{~h}$ of exposure to colcemid solution (Gibco).

After hypotonic treatment with $0.075 \mathrm{M} \mathrm{KCl}$ for $20 \mathrm{~min}$ at $37.5^{\circ} \mathrm{C}$, the cells were fixed in methanol-acetic acid 3:1 for $1 \mathrm{~h}$, centrifuged, fixed again, and left overnight in a refrigerator. The next day the cell suspension was centrifuged, fixed again in fresh fixative, spread on to clean wet slides and air dried.

The staining procedure for RBA-banding was performed as described by Di Berardino and lannuzzi (1982).

\section{Results}

Fig. 1 shows a representative prometaphase RBA-banded karyotype of the sheep $(2 n=$ $54, X Y$ ).

The karyotype has been arranged by following the same nomenclature as previously adopted for the RBA-banded karyotype of the goat (Di Berardino et al., 1987) and cattle (Di Berardino et al., 1985) which refers, as far as possible, to the Reading system (Ford et al., 1980).

Several karyotypes were prepared from the 11 investigated animals, but only the best banded chromosomes, 4 for each pair, were selected and used to produce the diagrammatic representation shown in Fig. 2A, B, C.

The whole idiogram of the RBA-banding pattern of sheep chromosomes is presented in Fig. 3A, B. The numbering of the bands within each individual chromosomes follows the ISCN nomenclature (ISCN, 1978).

The RBA-banding pattern of the individual sheep chromosomes has been found to be identical to that of the goat chromosomes previously reported (Di Berardino et al., 1987); therefore, the detailed description is omitted.

Given the complete homology in banding pattern between the chromosomes of the 2 species, and following a phylogenic criterion, the goat chromosome nomenclature, which is identical to that of cattle, was adopted to classify the sheep chromosomes.

For this reason there is no correspondence between the G-banded standard karyotype presented by Long (1985) and the present one.

Table I shows the nomenclature of the corresponding homologous chromosomes between sheep and goat; the 3 pairs of submetacentric chromosomes in the sheep karyoty- 


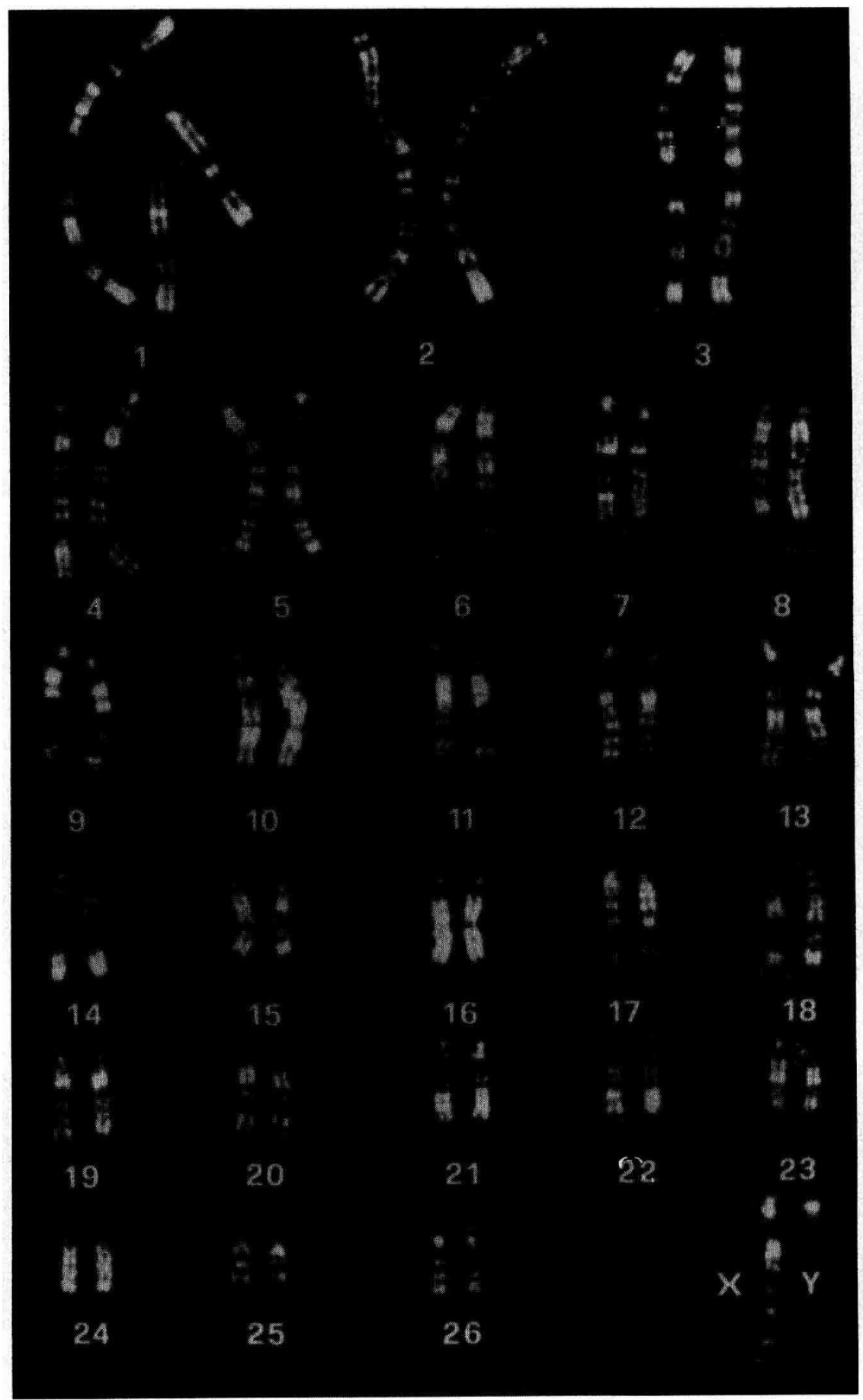

Fig. 1. Representative RBA-banded karyotype of the domestic sheep $(2 n=54, X Y)$, proposed as standard. 
D. Di Berardino et al.

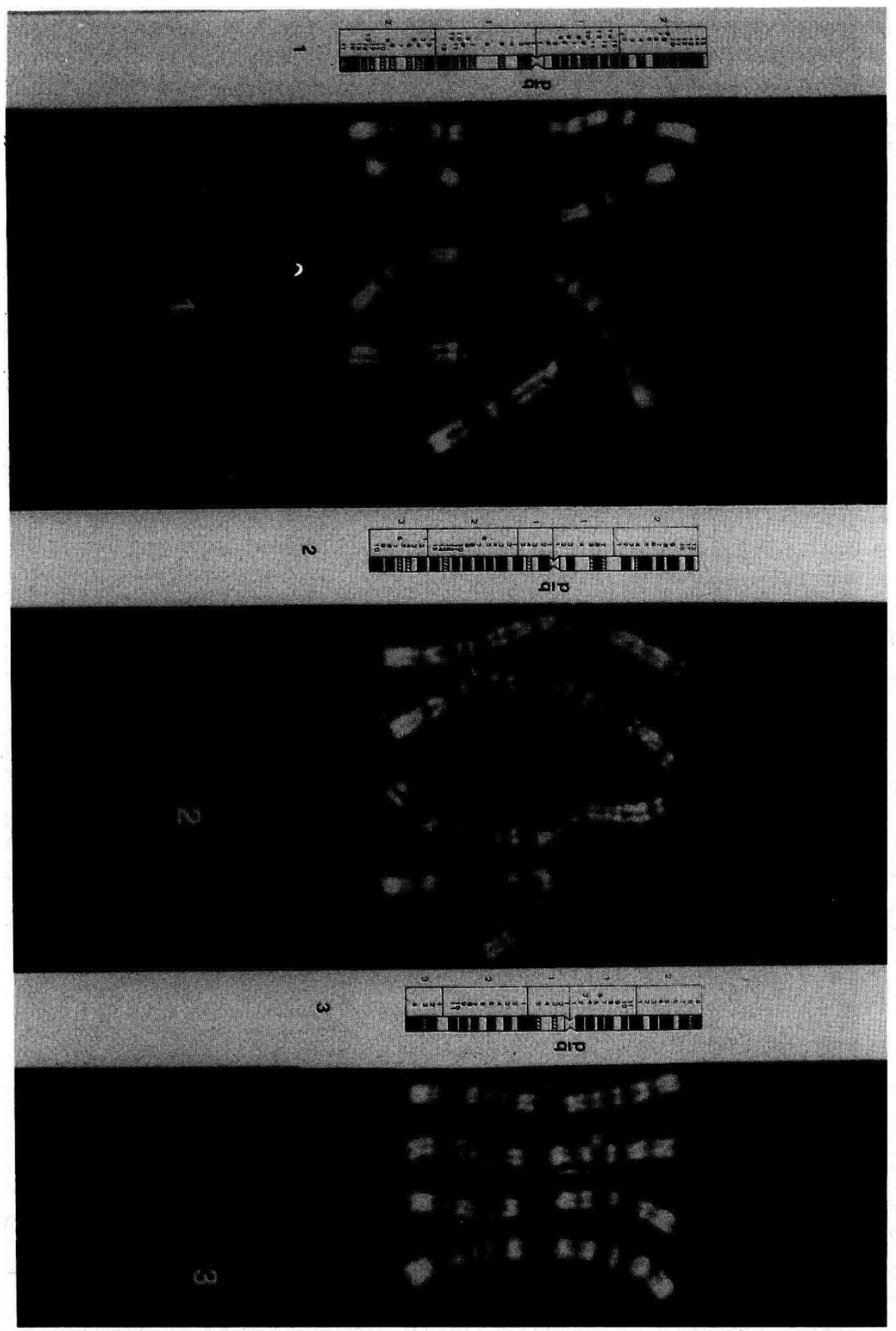

Fig. 2A,B,C. RBA-banding pattern of individual prometaphase chromosomes of the domestic sheep. Groups of 4 representative chromosomes, selected from different karyotypes, were used to construct the diagrammatic RBA-banding pattern shown on the left of each group. 


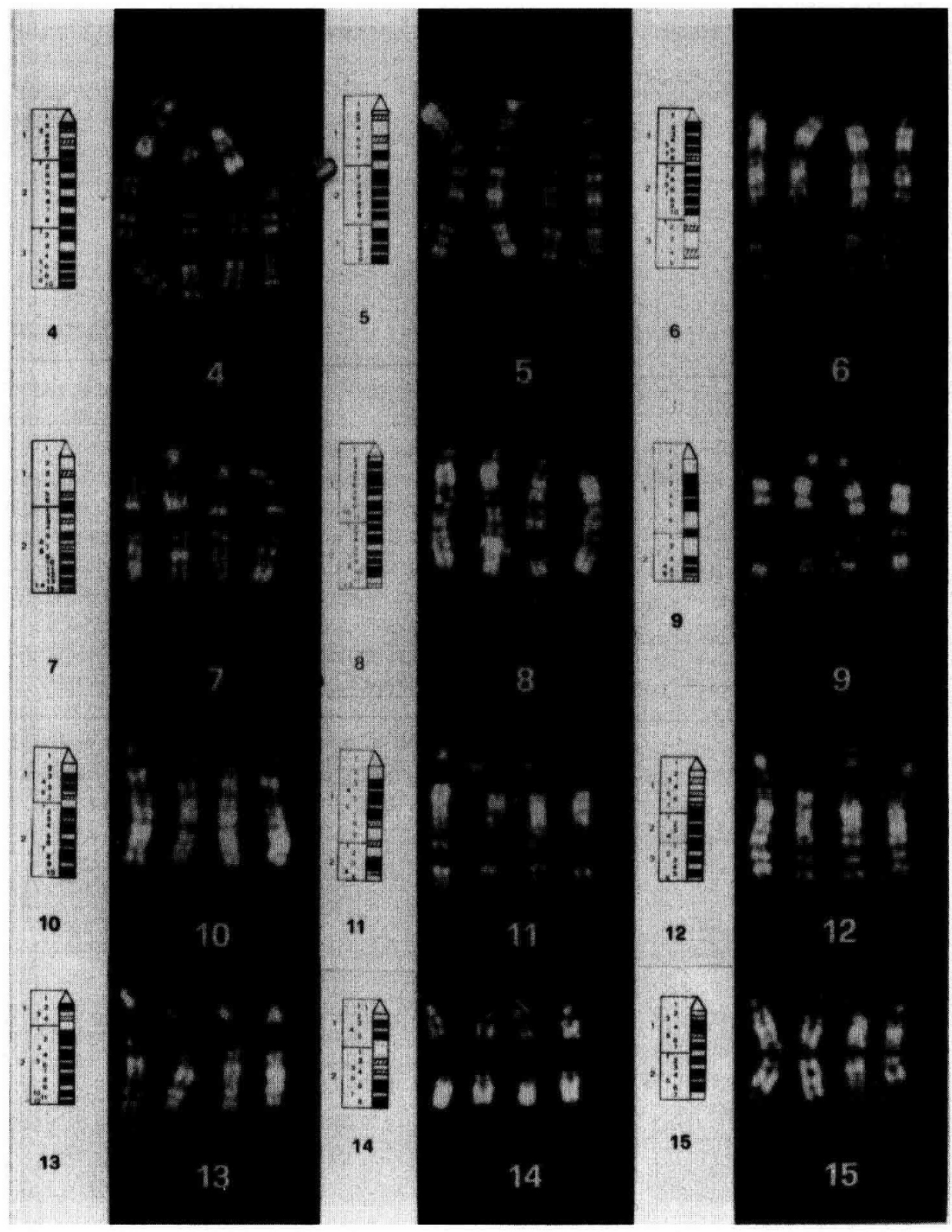

Fig. 2B. Legend as in Fig. 2A. 
D. Di Berardino et al.

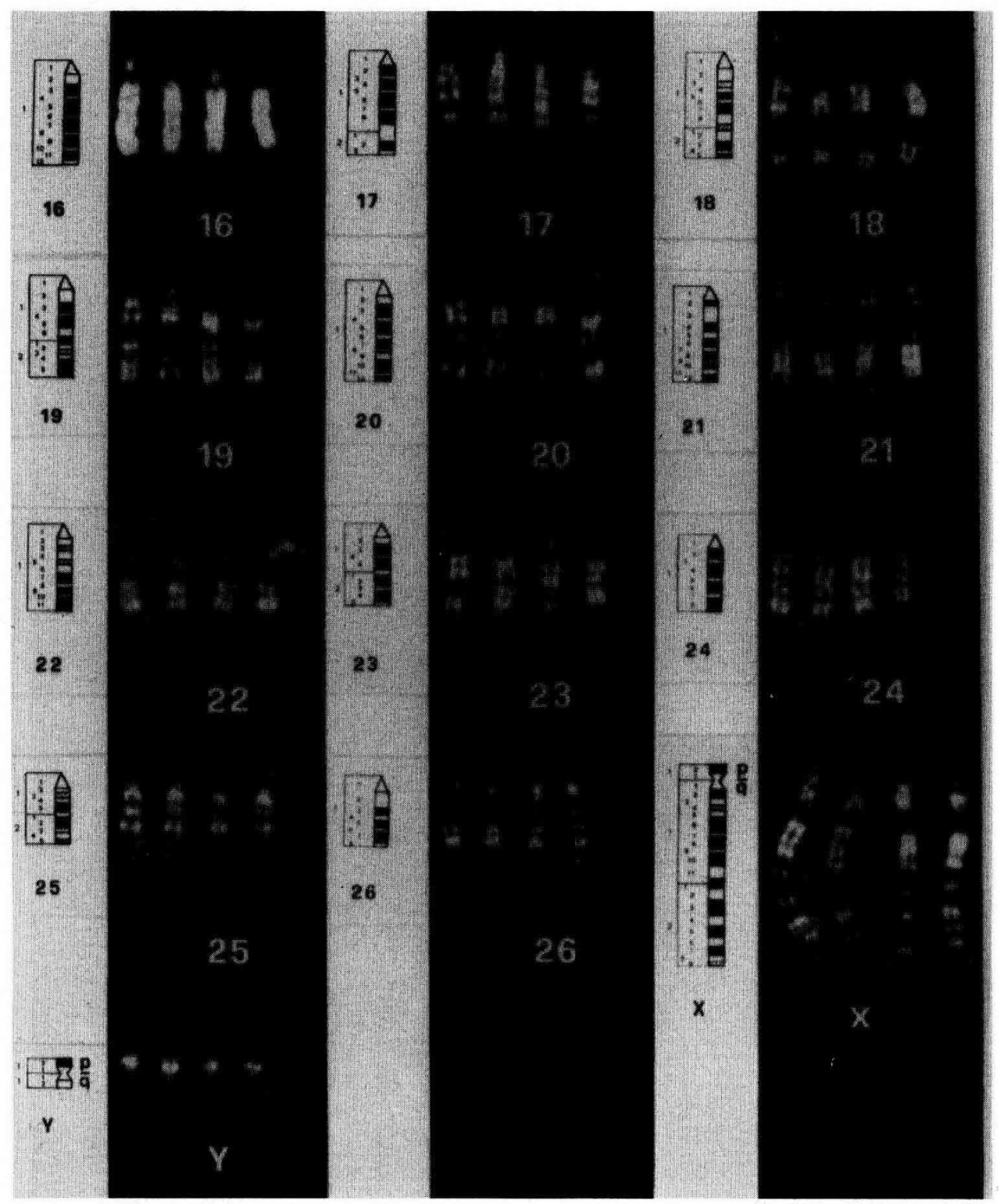

Fig. 2C. Legend as in Fig. 2 A. 


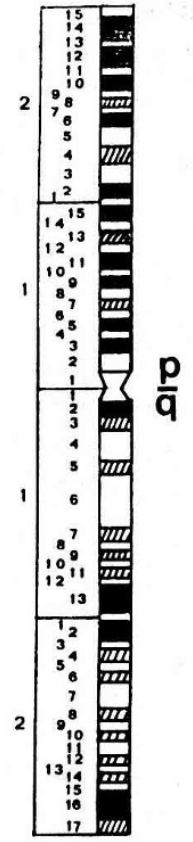

1

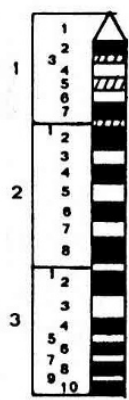

4

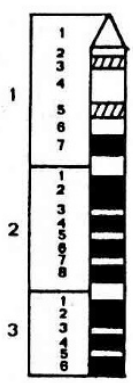

5

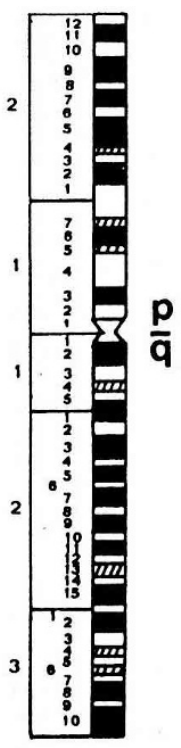

2

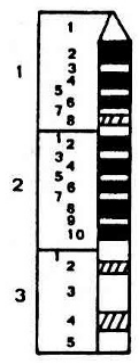

6

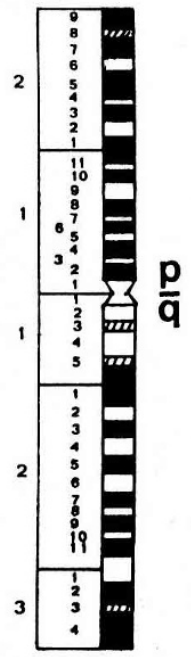

3

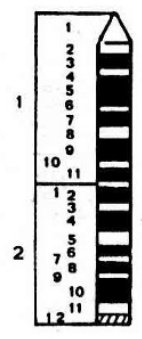

7

Fig. 3A,B. Diagrammatic representation of the RBA-banding pattern of prometaphase chromosomes of sheep. 


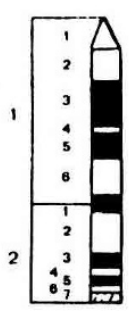

9

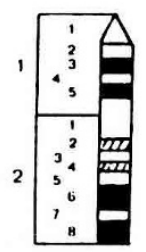

14

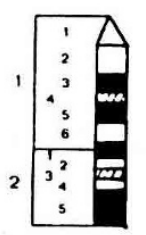

19

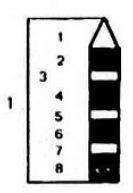

24

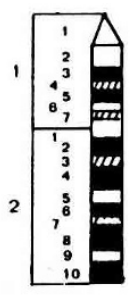

10

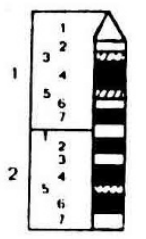

15

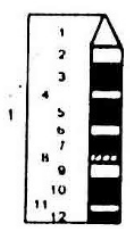

20

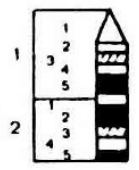

25

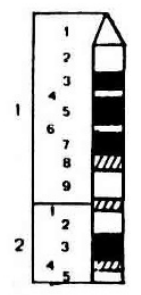

11

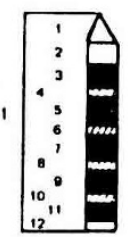

16

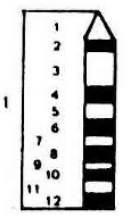

21

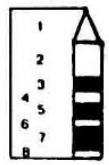

26
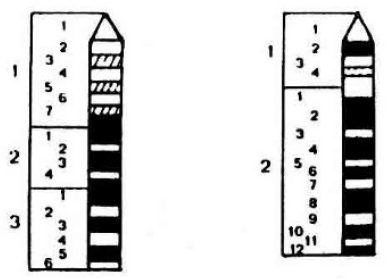

12 13

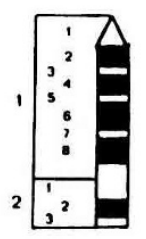

17

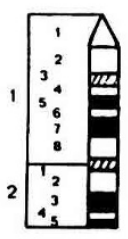

18

- Positive $\mathbf{R}$ bands

[.] Negative $\mathbf{R}$ bands

VIIZS Variable $\mathbf{R}$ bands

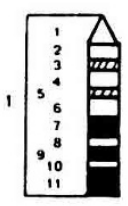

22

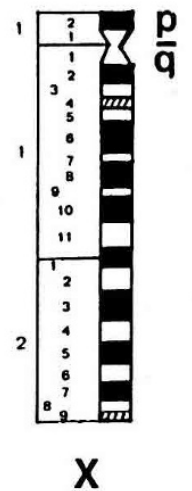

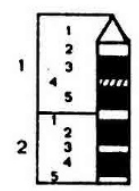

23

Fig. 3B. Legend as in Fig. 3A. 
Table I. Corresponding homologous chromosomes in the sheep and goat RBA-banded karyotypes.

\begin{tabular}{l|l|l|l|l|l|l|l|l|l|l|l|l|l|l|l|l}
\hline Sheep $\ldots .$. & $1 \mathrm{p}$ & $\mathrm{q}$ & $2 \mathrm{p}$ & $\mathrm{q}$ & $3 \mathrm{p}$ & $\mathrm{q}$ & 4 & 5 & 6 & 7 & 8 & 9 & 10 & 11 & 12 & 13 \\
\hline Goat $\ldots .$. & 3 & 1 & 8 & 2 & 11 & 5 & 4 & 6 & 7 & 9 & 10 & 12 & 13 & 14 & 15 & 16 \\
\hline \hline Sheep $\ldots . .$. & 14 & 15 & 16 & 17 & 18 & 19 & 20 & 21 & 22 & 23 & 24 & 25 & 26 & $\mathrm{X}$ & $\mathrm{Y}$ \\
\hline Goat $\ldots . . .$. & 17 & 18 & 19 & 20 & 21 & 22 & 23 & 24 & 25 & 26 & 27 & 28 & 29 & $\mathrm{X}$ & $\mathrm{Y}$ \\
\hline \hline
\end{tabular}

pe are the results of 3 different sets of centric fusions involving, respectively, chromosomes 1-3, 2-8, and 5-11 of the goat karyotype.

The total number of bands counted in the haploid set of sheep chromosomes in the prometaphase stage, including the $X$ and $Y$ chromosomes, equalled 510 bands, of which $187(36.7 \%)$ were positive, $251(49.4 \%)$ negative, and $72(14.1 \%)$ intermediate.

\section{Discussion and Conclusion}

The present paper has to be considered as a contribution to the establishment of the standard RBA-banded karyotype of the species Ovis aries L.

Lymphocytes were synchronized by excess of thymidine and RBA-banding was induced by using a combination of BrdU and $\mathrm{H} 33258$, as previously reported for the R-banded karyotype of the goat (Di Berardino et al., 1987). Thymidine synchronization is achieved by a feed-back inhibition mechanism which blocks the formation of deoxycytidine triphosphate from cytidine 5-phosphate (Xeros, 1962), thus blocking the majority of the celis at mid S-phase of the cell cycle. Thymidine was preferred to methotrexate or fluorouracil as it is less toxic and less clastogenic for cells (Dutrillaux and Viegas-Pequignot, 1981; Ronne et al., 1984; Ronne, 1984).

A remarkable increase in the R-band resolution was achieved by combining with BrdU H33258, which links to DNA by hydrophobic bonds (Bontemps et al., 1975; Comings, 1975) with a 4-fold stronger affinity to poly (dA-dbrdU) than poly (dA-dT) segments (Latt and Wohlleb, 1975); this combined incorporation delays chromosome contraction and enhances band contrast (Ronne, 1983).

The present RBA-banded karyotype can be utilized for further studies on detection of numerical as well as structural chromosomal abnormalities, evolutionary relationships among the members of the family Bovidae, and gene mapping by using in situ hybridization procedures (Geffrotin et al., 1984). The extensive degree of banding homology among the chromosomes of sheep, goat, buffalo, and cattle may be helpful for the localization of common genes responsible for important economic traits in animal production. 


\section{Acknowledgments}

This work has been supported by a financial contribution from the National Research Council, Rome, Italy.

\section{References}

Bontemps J., Houssier C. \& Fredericz E. (1975) Physiochemical study of the complexes of 33258 Hoechst with DNA and nucleohistone. Nucleic Acids Res. 2, 971-984

Comings D.E. (1975) Mechanisms of chromosome banding. VIII. Hoechst 33258-DNA interactions. Chromosoma, 52, 229-243

Di Berardino D. \& lannuzzi L. (1981) Chromosome banding homologies in Swamp and Murrah buffalo. J. Hered. $72,183-188$

Di Berardino D. \& lannuzzi L. (1982) Detailed description of R-banded bovine chromosomes. $J$. Hered., 73, 434-438

Di Berardino D. \& lannuzzi L. (1984) Detailed description of RBA-banded chromosomes of river buffalo (Bubalus bubalis L.). Génét. Sél. Evol., 16, 249-260

Di Berardino D., lannuzzi L. \& Lioi M.B. (1985) The high resolution RBA-banding pattern of bovine chromosomes. Cytogenet. Cell Genet. 39, 136-139

Di Berardino D., lannuzzi L., Ferrara L. \& Matassino D. (1979) A new case of Robertsonian translocation in cattle. J. Hered. $70,436-438$

Di Berardino D., lannuzzi L., Bettini T.M. \& Matasino D. (1981) Ag-NORs variation and banding homologies in two species of Bovidae: Bubalus bubalis and Bos taurus. Can. J. Genet. Cytol. 23, 89-99

Di Berardino D., Ronne M., Burgete I., Lioi M.B., Taibi L. \& Matassino D. (1987) The R-banding pattern of the prometaphase chromosomes of the goat (Capra hircus L.). J. Hered. 78, 225-230

Dutrillaux B. \& Viegas-Pequignot E. (1981) High resolution R- and G-banding on the same preparation. Hum. Genet. 57, 93-95

Dutrillaux B., Laurent C., Couturier J. \& Lejeune J. (1973) Coloration des chromosomes humains par l'acidrine orange après traitement par la 5-bromodeoxyuridine. C. R. Acad. Sci. Sér. D. 276, 31793182

Ford C.E., Pollock D.L. \& Gustavsson I. (1980) Proceedings of the 1st International Conference for the Standardisation of Banded Karyotypes of Domestic Animals. Hereditas 92, 145-162

Geffrotin C., Popescu C.P., Cribiu E.P., Boscher J., Renard C., Chardon P. \& Vaiman M. (1984) Assignment of MHC in swine to chromosome 7 by in situ hybridization and serological typing. Ann. Génét. 27, 213-219

Gustavsson 1. \& Hagelthorn M. (1976) Staining technique for definite identification of individual cattle chromosomes in routine analysis. J. Hered. $67,175-178$

ISCN (1978) An international system for human cytogenetic nomenclature. Cytogenet. Cell Genet. $21,309-404$

Latt S.A. \& Wohlleb J.C. (1975) Optical studies of the interaction of 33258 Hoechst with DNA, chromatin and metaphase chromosomes. Chromosoma 52, 297-316

Long S.E. (1985) Standard nomenclature for the G-banded karyotype of the domestic sheep (Ovis aries L.). Hereditas 103, 165-170

Popescu C.P. (1975) Essai d'identification des chromosomes bovins (Bos taurus) à l'aide du marquage au 5-bromodeoxyuridine (BrdU). In : $2^{\ominus}$ Colloque Européen de Cytogénétique des Animaux Domestiques, Giessen, 29-30 septembre 1975. INRA-CNRS, France, pp. 59-64

Ronne M. (1983) Simultaneous R-banding and localization of dA-dT clusters in human chromosomes. Hereditas $98,271-278$

Ronne M. (1984) Fluorouracil synchronization of human lymphocyte cultures. Induction of high resolution R-banding by simultaneous in vitro exposure to 5-bromodeoxyuridine/ Hoechst 33258 . Hereditas 101, 215-208

Xeros N. (1962) Deoxyriboside control and synchronization of mitosis. Nature 194, 682-683 